\title{
Seasonal Use of Soil Water by Mature Velvet
} Mesquite

\author{
DWIGHT R. CABLE
}

Highlight: Mesquites used water consistently to a depth of $3 \mathrm{~m}$ and outward to $10 \mathrm{~m}$ beyond the crowns, but use at $15 \mathrm{~m}$ was limited mainly to drier periods when water supplies closer to the trees were depleted. With the start of spring growth, water was extracted most rapidly from the surface layers. As the season advanced, the watersupply zone became increasingly thicker. Rates of extraction were highest immediately after recharge in early spring and early summer, and lowest in late fall. Differences in available water in the soil accounted for 72 to $88 \%$ of the variation in rates of extraction. The competitive effect of velvet mesquite on perennial grasses is most severe in the upper $37.5 \mathrm{~cm}$ of soil under and near the mesquite crowns, and gradually decreases with distance into adjacent openings. The competitive effect in the openings is much more severe in dry years than in wet years.

Velvet mesquite (Prosopis juliflora var. velutina) competes severely for soil water with perennial grasses. When mesquite is killed or reduced in amount, perennial grass production increases, sometimes dramatically (Parker and Martin 1952; Cable and Tschirley 1961; Martin and Cable 1962, 1974; Cable and Martin 1964).

These results have been attributed to the extensive lateral root system of velvet mesquite, which occupies the same soil mass from which grasses must obtain their water. The assumption is that mesquite roots exert a stronger "pull" on the soil water than do the grasses.

The present study was undertaken to determine the water use pattern of mature velvet mesquite at all stages in the annual growth cycle within a soil mass $6 \mathrm{~m}$ deep extending $15 \mathrm{~m}$ horizontally beyond the edge of the tree crowns.

Water moves from the soil into the plant roots, and through the plant as liquid flow in response to gradients in water potential between the soil and the

The author is principal range scientist, Rocky Mountain Forest and Range Experiment Station, Forest Service, U.S. Department of Agriculture; central head quarters maintained in cooperation with Colorado State University at Fort Collins, Colorado. Research reported here was conducted while Cable was at the Station's Research Work Unit at Tucson, in cooperation with University of Arizona; he is now with the Unit at Albuquerque, New Mexico.

The work described was partly supported through the US/IBP Desert Biome Program under Grant GB32139X from the National Science Foundation.

Manuscript received March 10, 1976. plant root, the plant root and the leaf, and between the leaf and the air (Slatyer 1967). Resistance to water flow is greater during entrance into the roots, than to longitudinal flow in the xylem elements of the root and stem (Kramer 1969).

Because of the relatively low resistance to longitudinal movement of water in the root xylem, water is absorbed from distances of several meters as readily as from closer distances. Thus extraction of water from the soil tends to be more closely related to concentration of roots than to distance from the tree (Kramer 1969). But because root concentrations generally tend to decrease with depth in the soil and with horizontal distance from the tree, water is usually extracted most rapidly in the upper part of the root zone and closer to the trunk. As soil water in these areas decreases, the zone of maximum water uptake moves downward and outward (Cowan and Milthorpe 1969; Slatyer 1967).

\section{Methods}

The study area was located at an elevation of about $1,220 \mathrm{~m}(4,000 \mathrm{ft})$ on the Santa Rita Experimental Range south of Tucson, Ariz. Annual precipitation at the study site averages about $37 \mathrm{~cm}$ ( 15 inches) with about $58 \%$ falling during the JulySeptember summer growing season. Most of the remainder falls during the DecemberApril winter rainy season. The two rainy seasons are separated by dry periods, with where water moves across the cortex, the May-June drouth being particularly severe (Fig. 1). The soil is Comora gravelly sandy loam in the loamy, skeletel, mixed, thermic family of Cumulic Haplustolls, changing to gravelly clay mostly between 2.5 and $4 \mathrm{~m}$ depth.

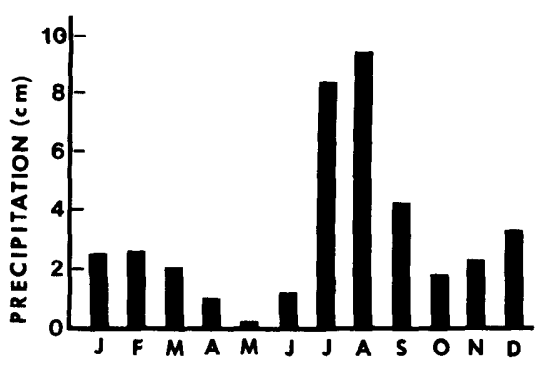

Fig. 1. Mean monthly precipitation at the study site (51-year means).

The relatively high rainfall and sandy soil provide a favorable site for velvet mesquite. The area supports a stand of about 50 mature trees per hectare (20 trees/acre). Four mature trees, each located at the edge of an opening 20 to $30 \mathrm{~m}$ across, were selected for study. These trees were 5-6 m tall, with crowns $8-9 \mathrm{~m}$ in diameter. At each study tree, six 5-cm holes were drilled into the ground, each $6 \mathrm{~m}$ deep, along one radius from the trunk. Holes 1 to 3 were under the tree crown: near the trunk, midway between the trunk and the edge of the crown, and at the edge of the crown; holes 4 to 6 were located 5,10 , and $15 \mathrm{~m}$ beyond the edge of the crown, in the adjacent opening (Fig. 2). Four other trees were killed with diesel oil applied to the base of the trunk, and three holes were drilled, at positions 1,3 , and 5 , to provide check data on changes in moisture in soil supporting no live vegetation. Aluminum access tubes were inserted in the holes for a neutron probe. Trees surrounding the openings, and all other vegetation near the holes, were killed so that no live roots other than those of the study trees would be present near the live-tree holes and no live roots of any kind near the dead-tree holes.

Soil water was measured with a neutron probe, calibrated to read percent by volume, at 13 depths from $25 \mathrm{~cm}$ to $6 \mathrm{~m}$ ( $25-\mathrm{cm}$ intervals to $2 \mathrm{~m}$; at $2.5,3,4,5$, and $6 \mathrm{~m}$ ). 


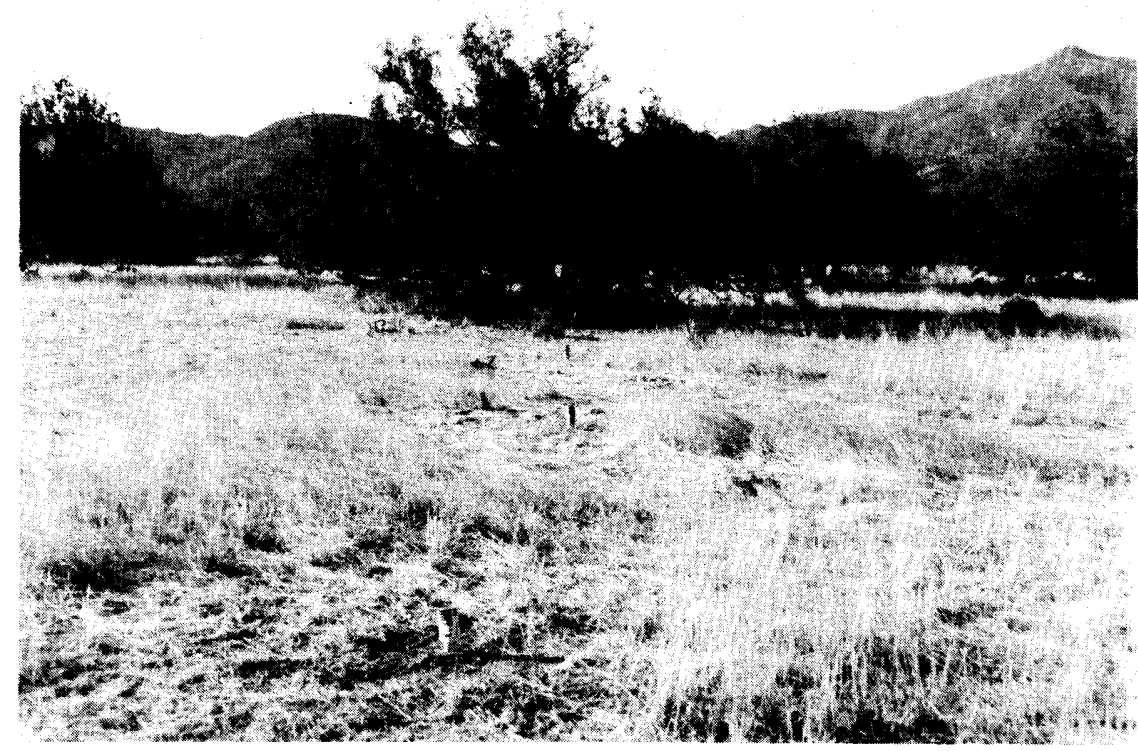

Fig. 2. Protruding ends of aluminum access tubes, used to sample soil water content by neutron probe, along a radius from a velvet mesquite tree.
Measurements were taken at about 2-week intervals between July 1971 and December 1973, except during the summer of 1971 , when measurements were taken every 3 or 4 days.

For most comparisons, soil water is expressed in terms of "volume percent available," defined as soil water in excess of the permanent wilting percentage (Slatyer 1967; Meyer and Anderson 1952). For this study, the soil water contents on July 10, 1971, are assumed to represent permanent wilting percentages. This was at the end of a very dry period, just prior to the start of summer rains, and the trees were obviously stressed for water, as indicated by meager leaf, flower, and fruit development. These were also the lowest soil water values at most depths for the $2 \frac{1 / 2}{2}$-year study period. Negative values of available soil water recorded late in 1973 at some depths indicate that the mesquite roots were able to reduce soil water content to slightly below the assumed permanent wilting percentages.

For convenience, in referring to water contents in the soil at the various distances from the tree, the convention has been adopted of referencing these distances to the particular "hole(s)" from which the data were obtained.

From the $2 \frac{1}{2}$-year record, two periods have been selected to characterize the soil water use regime for velvet mesquite: (1) July-December 1971; soil water recharge and depletion for a summer of near-normal rainfall, followed by an unusually wet fall, and (2) March-November 1973; soil water depletion during a very dry spring, summer, and fall, following an unusually wet fall and winter recharge period.

\section{Results and Discussion}

\section{Initial Conditions}

At the start of the study, in July 1971, volume percent water at the study trees ranged from about $2 \%$ at 25 $\mathrm{cm}$ to $4.4 \%$ at $1 \mathrm{~m}$ in the sandier soil, to over $14 \%$ in the deeper clayey soil. These soil water values were probably near wilting point at all depths.

\section{Precipitation during Study Period}

The year has been divided into four seasons for presenting precipitation data, keyed to the annual growth cycle of mesquite: (1) January-March: medium precipitation, the major soil water recharge period, mesquite dormant, (2) April-June: low precipitation, spring leafing-out and flowering period, (3) July-September: high rainfall, high temperatures, and rapid soil water use, and (4) October-December: relatively dry, cool, ending with winter dormancy.
Seasonal precipitation totals varied widely from long-time means during most of the study period. On an annual basis, 1971 averaged $29 \%$ above the long-time mean (for the two seasons available), and 1972 and 1973 (with 27.5 and $23.3 \mathrm{~cm}$, respectively) averaged 31 and $41 \%$, respectively, below the long-time means (Table 1). Of the 10 seasons, only two were nearnormal: summer 1971 and spring 1972. Five varied from 40 to $99 \%$ below the long-time means, while the other three varied from 82 to $107 \%$ above the long-time means.

\section{Phenological Development of Velvet Mesquite}

Velvet mesquite begins leafing out between late March and late April, as shoots elongate. Flower buds develop during the same period, and the first pods appear about 5 weeks after flower buds burst, usually in May at the study area elevation. Twig elongation and leaf initiation last 3 to 4 weeks, and flowering 4 to 6 weeks. Pods mature 7 to 9 weeks after flower buds burst, in late May or June. Mesquite can flower and form pods later in the summer if rainfall is high, but this did not happen during the study period. Leaves normally begin to yellow and dry in late fall, and all leaves have usually dropped by late December.

\section{Soil Water Changes}

The broad pattern of soil water change shows: (1) recharge during the winter precipitation period, followed by (2) periods of high water extraction during the spring while leaves, stems, flowers, and fruit are developing, and during the summer when rainfall is usually high, and (3) periods of low water extraction in the fall, when rainfall and soil water levels are low, and later in the winter after the leaves have dropped and the trees are dormant.
Table 1. Seasonal precipitation $(\mathrm{cm})$ at the study area (inches in parenthesis).

\begin{tabular}{lclccc}
\hline $\begin{array}{l}\text { Year and } \\
\text { means }\end{array}$ & $\begin{array}{l}\text { Jan.- } \\
\text { Mar. }\end{array}$ & $\begin{array}{l}\text { Apr.- } \\
\text { June }\end{array}$ & $\begin{array}{l}\text { Jul.- } \\
\text { Sept. }\end{array}$ & $\begin{array}{l}\text { Oct.- } \\
\text { Dec. }\end{array}$ & Total \\
\hline 1971 & - & - & 22.5 & 15.7 & - \\
1972 & 0.1 & 3.2 & 10.3 & 13.9 & 27.5 \\
1973 & 13.5 & 1.5 & 7.1 & 1.2 & $\begin{array}{c}(10.84) \\
23.3\end{array}$ \\
Mean & 6.8 & 2.4 & 13.3 & 10.3 & 32.8 \\
& $(2.68)$ & $(.94)$ & $(5.24)$ & $(4.05)$ & $(12.91)$ \\
Est. long-time mean & 7.4 & 2.5 & 22.1 & 7.6 & 39.6 \\
Percent of total & 18.7 & 6.3 & 55.8 & 19.2 & 100.0 \\
\hline
\end{tabular}



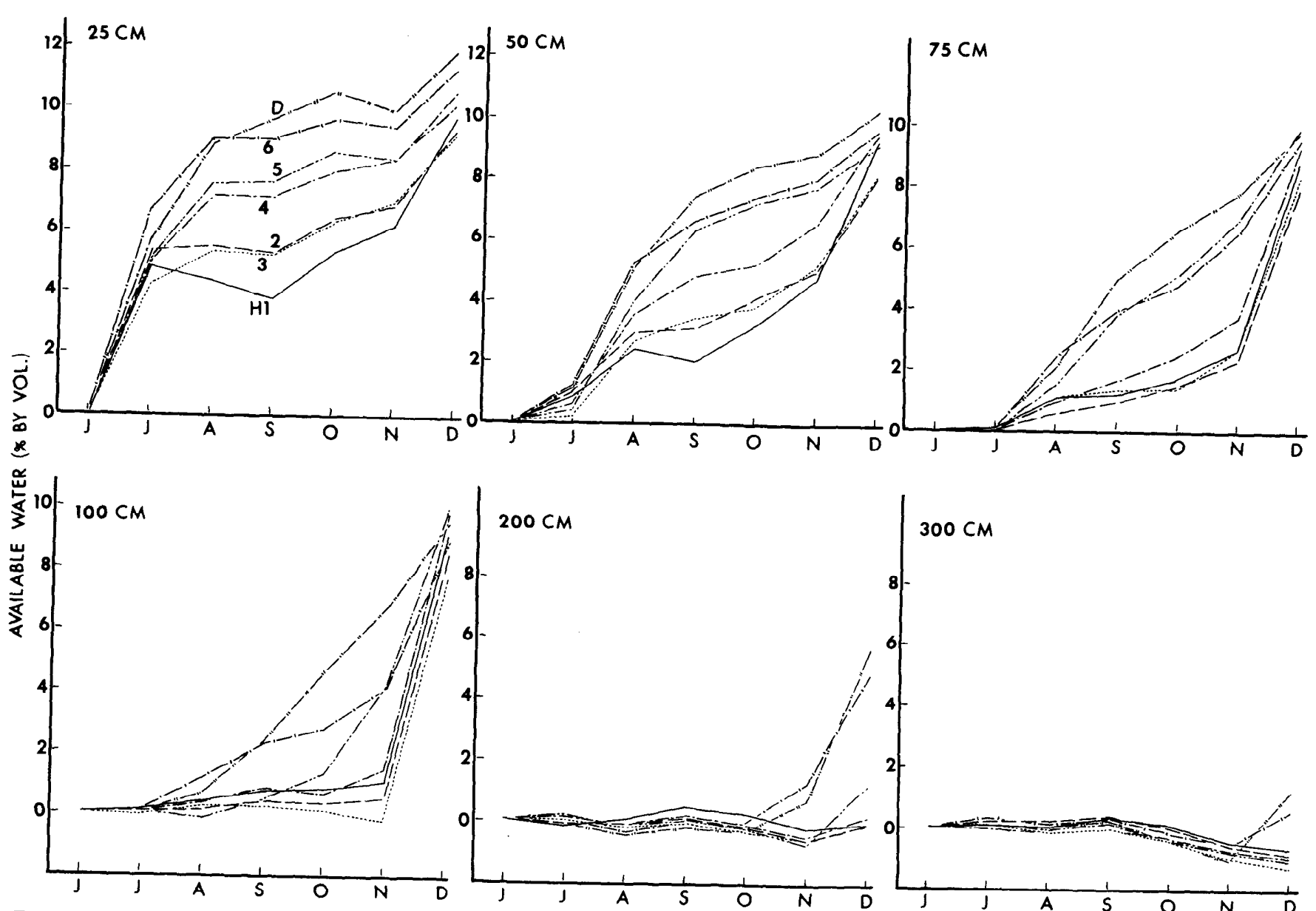

$300 \mathrm{CM}$

Fig. 3. Soil water recharge during summer and fall 1971 at 6 soil depths for holes $1-6$ and at dead trees (monthly averages of vol $\%$ available).

\section{Recharge}

The amount and degree of recharge of soil water depend on: (a) amount of precipitation, and (b) evapotranspiration rates. Evapotranspiration losses are due to extraction of water by plant roots and to surface evaporation, which in turn is a function mainly of temperature and humidity. The major recharge period at the study site is during the winter rainy period, primarily because temperatures are low and most plants are dormant; recharge reached the $3 \mathrm{~m}$ depth at some holes during both winter recharge periods (1971-72 and 197273 ). During the summer rainy season, on the other hand, high temperatures and high evaporation rates, coupled with rapid extraction by plant roots, severely restrict recharge. Water reached the $1 \mathrm{~m}$ depth at some holes in the summers of 1971 and 1972 but reached only the $50-\mathrm{cm}$ depth in 1973.

Figure 3 illustrates the recharge pattern at the six live-tree holes and at the dead trees, for six depths in the soil, during the summer of 1971, when rainfall was near-normal, and during the following unusually wet fall, when rainfall was $128 \%$ above the long-time mean. The strong impact of soil water extraction is evident in the greatly restricted recharge at holes 1 to 3 , under the tree crowns, compared to the increasing levels of recharge at successively farther distances. The restricted recharge was most noticeable during August and September, when evapotranspiration demands were highest, as shown by maximum differences between hole 1 and the dead trees of about $6 \%$. The rates of recharge increased noticeably with the cooler temperatures of fall, especially at holes 1 to 4 , and particularly with the near-dormancy of the mesquite in December, when variation among holes was reduced to 2 to $3 \%$.

Also evident from Figure 3 is the time lag for water to reach successively deeper depths, and the influence of extraction by tree roots in restricting the downward movement of water. It should be noted that, although the December values represent maximum recharge at depths to $125 \mathrm{~cm}$, with $8 \%$ to $10 \%$ available water, maximums were reached successively later at deeper depths: January at $150 \mathrm{~cm}$, February at $200 \mathrm{~cm}$, March at $250 \mathrm{~cm}$, April at $300 \mathrm{~cm}$ at the live trees. Also, the maximums decreased with increasing depth, from a mean of $8.7 \%$ available water at $125 \mathrm{~cm}$ in December to $0.8 \%$ in April at $300 \mathrm{~cm}$ for live trees. Dead-tree maximums were higher (9.8 to $2.6 \%$ ) and were reached earlier (December to February) for depths from 125 to $300 \mathrm{~cm}$. Of course, the particular level of available soil water attained after a recharge period, as illustrated in Figure 3 and later figures, represents $100 \%$ of the soil water available for plant use at that particular location until the next recharge event.

"Maximums", at the deeper depths were lower, suggesting only partial wetting during recharge, because recharge reached different depths at the four study trees, yielding mean values less than field capacity.

Presenting the 1971 summer recharge data as monthly averages (Fig. 3 ) adequately illustrates the overall recharge pattern, but masks short-term changes. Typically, frequent summer 
rains superimposed on a strong and continuous evapotranspiration demand result in frequent alternating periods of recharge and depletion, especially at the 25-cm depth.

\section{Extraction}

The year 1973 provided a good opportunity to study soil water extraction by velvet mesquite from.growth initiation in the spring until neardormancy in late fall. The conditions that produced this opportunity included: (1) unusually good soil water recharge caused by $83 \%$ above normal precipitation from October 1972 through March 1973, (2) lack of rain between March 30 and June 28, providing an uninterrupted period of depletion during spring leafing-out and flowering, and (3) a short, dry summer rainy season, with essentially no recharge below $50 \mathrm{~cm}$, followed by an even drier fall. As a result, depletion of the previous winter's recharge continued into the fall to the lowest levels of soil water encountered in the $2 \frac{1 / 2-}{}$ year study period at most holes and depths.

Even with the unusually high winter precipitation, water barely reached the $3 \mathrm{~m}$ depth at the live trees. The following discussion will, therefore, be limited to soil water changes in the upper $3 \mathrm{~m}$ of soil.

Spring growing period. By March 30,1973 , the winter rains had ended

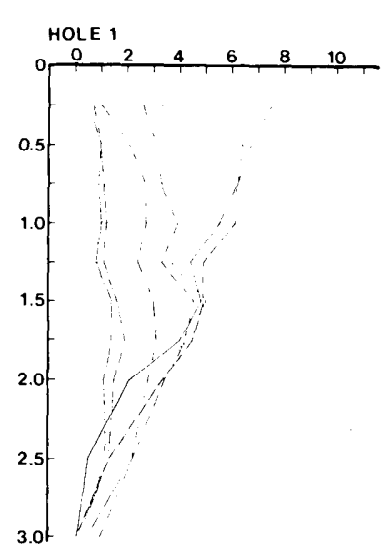
SOIL WATER AVAILABLE $\% \%$ BY VOL. HOLE 2
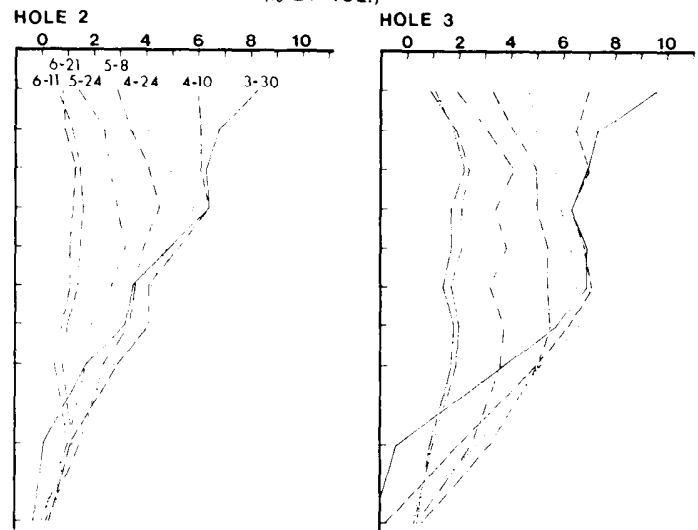

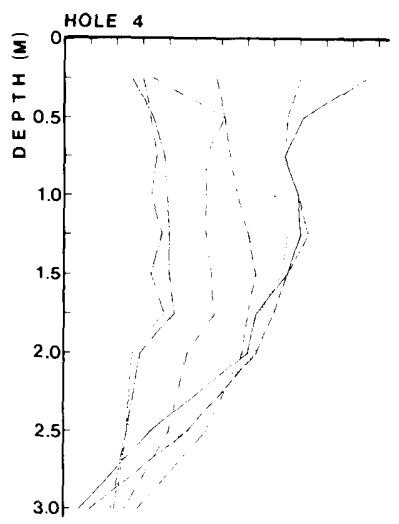

HOLE 5
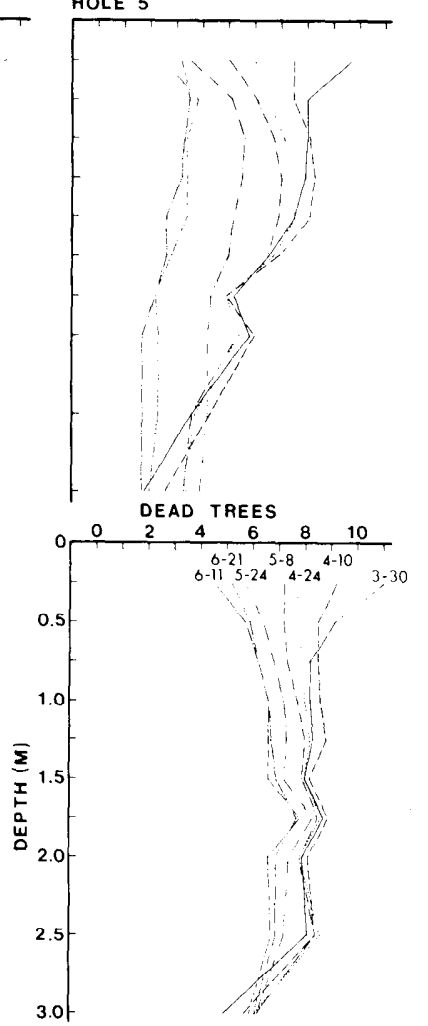

Fig. 4. Profiles of available soil water at successive intervals of approximately 2 weeks during spring 1973, at 6 live-tree holes (HI next to trunk; H6 15 m beyond edge of crown) and at dead trees. and available water had reached maximum values at depths down to about $150 \mathrm{~cm}$ (Fig.4). At greater depths, water content continued to increase, however, reaching maximum values at most depths by May 8. Water loss during the period March 30 to April 10 was restricted mainly to the $25-\mathrm{cm}$ depth, and was due almost entirely to evaporation. By April 10 the mesquite trees were beginning to grow, and thereafter a major part of the decrease in available water was due to extraction by the tree roots.

Changes in available water during successive 2-week periods from March 30 to June 21, 1973, show that extraction was most rapid at the $25-\mathrm{cm}$ depth (Fig. 4). As the season progressed, increasingly larger amounts of water were taken from increasingly deeper depths. Rates of soil water extraction were highest at most depths and holes during the period May 8 to June 11 . Most of the soil water used by the trees during this spring growing period came from the soil represented by holes 1 to 5 . Losses at hole 6 were essentially similar to those at dead trees.

Summer and fall 1973. Small but significant amounts of water were available throughout the profile at the beginning of the summer rainy season in July 1973, as a carryover from winter recharge (Fig. 5). Recharge from the July rains was restricted almost entirely to the 25-cm depth. By August 14, the summer water had been used, and extractions thereafter were small and rather uniformly taken from all depths, as a continuation of the pattern prior to the summer rains. These losses appear to be of roughly similar magnitude at live-tree holes 1 to 5 as at the dead trees, suggesting that evaporative forces were removing water from the soil at the dead trees as fast as evaporation plus transpiration were removing water at the live trees. These rates of removal are not directly comparable, however, because more than four times as much water was available at the dead trees as at the live trees on July 19, and the rate of extraction of soil water is strongly dependent on the amount of water present. This relationship is fully discussed in the next section.

Total extraction at hole $6,15 \mathrm{~m}$ beyond the crown, during this period was considerably higher at all depths than that at the other 5 live-tree holes or 


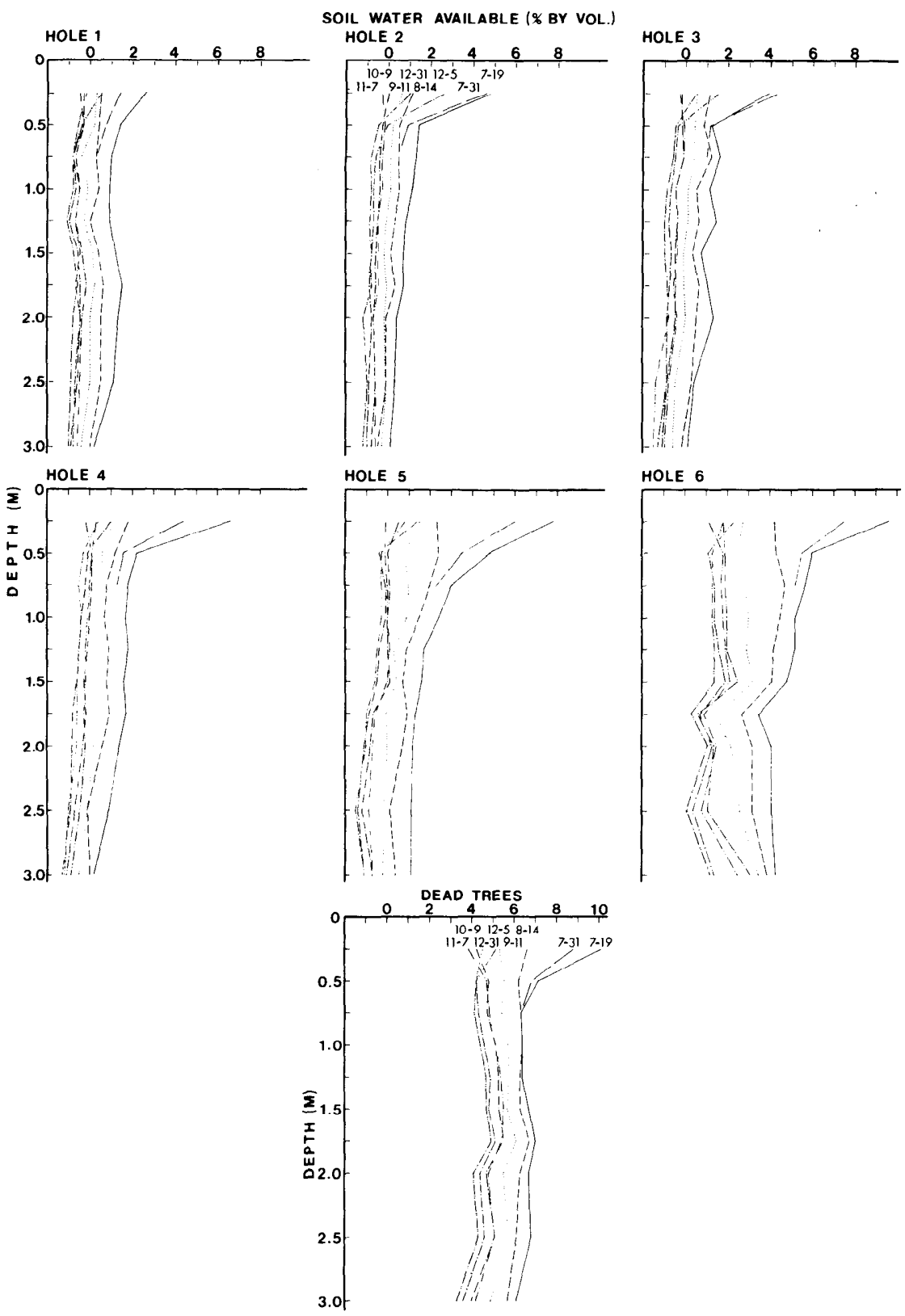

Fig. 5. Profiles of available soil water (\% by vol) at successive intervals of approximately 4 weeks during summer and fall 1973, at 6 live-tree holes (HI next to trunk; H6 15 m beyond edge of crown) and at dead trees.

at the dead trees. It was only after much of the soil water had been removed from holes 1 to 5 that the mesquite trees withdrew water from the farthest distance.

This pattern of water extraction during the summer of 1973, when available water carried over from the previous winter's recharge was present throughout the 3-m profile, contrasts sharply with the extraction pattern during the summer of 1971 , when there was no carryover. The summer of 1971 was characterized by only minor changes in water content below $75 \mathrm{~cm}$ ( $0.5 \%$ or less), and frequent alternating periods of recharge and depletion in the upper $75 \mathrm{~cm}$.

\section{Carryover of Soil Water from Spring to Summer}

Some available soil water was carried over from spring to summer in 2 of the 3 study years. Recharge precipitation for the fall and winter of 1970-71 was less than $50 \%$ of the long-time mean, and there was essentially no carryover to the summer of 1971 . Recharge precipitation for the falls and winters of 1971-72 and 1972-73, on the other hand, were 124 and $183 \%$ of the long-time means, respectively.
Amounts of available soil water carried over varied between about 1 and $2 \%$ for holes 1 to 3 , under the tree crowns, and 4 to $5 \%$ at hole $6,15 \mathrm{~m}$ beyond the edge of the crown. Apparently, in years when recharge precipitation of the previous fall and winter is below the long-time mean, available soil water is essentially exhausted before the summer rains begin, but in years when recharge precipitation is appreciably higher than the long-time mean, some soil water is carried over to summer, particularly in openings between trees.

\section{Relationship Between Soil Water Content and Rate of Extraction}

The rate at which water was extracted from the soil by mesquite roots was highest when soil water content was highest and decreased linearly as soil water content decreased. These results agree with previous research as reviewed by Slatyer (1967) and Gardner (1968). The approach adopted in studying differences in rates of extraction was to plot available soil water (means of four trees) against time for the period from March 30 to December 31, 1973. These curves for the various holes and depths showed that the rate of soil water extraction remained constant for periods varying from 26 to 121 days, depending on seasonal weather conditions.

Under conditions of high soil water availability at the start of the spring constant-use period, the first 50 to $75 \%$ of available water ( 3 to $5 \%$ by volume) was lost at relatively rapid rates of from 0.20 to $0.05 \%$ by vol/day, depending on hole and depth. The remaining soil water was extracted much more slowly during the following summer and fall-at rates of from about 0.04 to $0.005 \%$ by vol/day. Growth stage of mesquite appeared to have little effect on rates of extraction of soil water. Apparent effects were coincidental.

In surface soil. Soil water extraction data for four seasons in 1973 at the $25-\mathrm{cm}$ depth illustrate the effects of evaporation superimposed on those of water use by the trees (Fig. 6). The main factors controlling loss of water were: (1) evaporative forces of the atmosphere, (2) transpiration demand by the trees, and (3) supply of water in the soil.

Losses were highest when the weather was hot and dry, when trees were growing rapidly or transpiring rapidly, and when soil water content was high. 


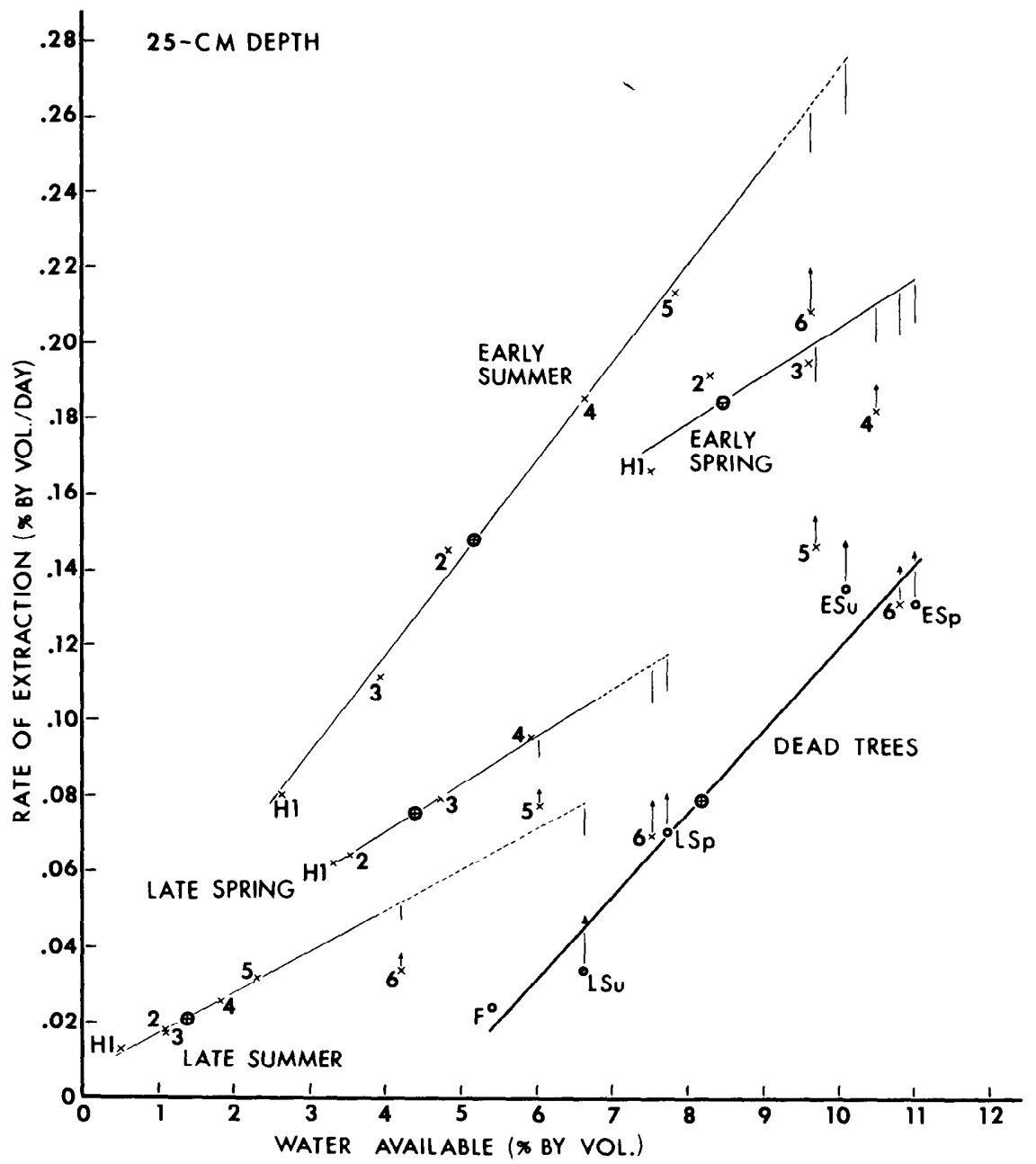

Fig. 6. Rates of extraction of soil water during four periods of uniform extraction at the 25-cm depth in 1973, related to vol \% water available at start of period. Regressions based on holes 1 to 3 for early spring, I to 4 for late spring, I to 5 for early and late summer (arrows at certain data points indicate reduced extraction at these distances-see text).

When water was in short supply, however, the rate of extraction was curtailed, regardless of evapotranspiration demands.

In early spring (March 30-April 24) water content was high, and transpiration demand was high because of active spring growth. The resulting high rate of extraction reduced the available water about $50 \%$ by the end of the early spring period. As a result, the rate of extraction during late spring (April 25-June 11) decreased about $60 \%$, even though evapotranspiration demand increased due to higher temperatures and continued active growth of mesquite. By June 11, at the end of the late spring period, available water averaged less than $1 \%$ at the four active water-supplying holes.

July rains added from about 2 to 5\% to the available supply, and as a result of adequate water and strong evapotranspiration demands, the average rate of extraction for the early summer starting water content. For example, in late spring (LSp) the dead-tree rate of extraction was $0.07 \%$ by vol/day, with a starting available water content of $7.7 \%$. A vertical projection of this point intersects the extension of the late spring live-tree regression at $0.117 \%$ by vol/day, $67 \%$ higher. Similarly, the early summer (ESu) rate of 0.135 at the dead trees (starting vol percent 10.1) intersects the live-tree regression at 0.275 , twice the dead-tree rate. Actual evaporation loss at the live trees was probably less than at the dead trees because of shading effect under the crowns and extraction by the roots of some water that would have evaporated if the roots had not absorbed it. Thus, the amounts attributed to use by the trees, as indicated in Figure 6, are conservative.

The upper $37.5 \mathrm{~cm}$ of soil, as represented by the $25-\mathrm{cm}$ depth data, is an important source of water for velvet mesquite. The practical value of these data to rangeland managers is to provide a quantitative basis for the well-documented fact that competition for water between velvet mesquite and perennial grasses is severe. Not previously documented is the fact that this competition is intensified during drier periods, because at these times the mesquite roots are most active in extracting water in the openings between trees. When water supply was high, in early spring, the trees were drawing water primarily from holes 1 to 3 , under the crowns, at the $25-\mathrm{cm}$ depth, with decreased extraction at hole 4 , and more especially at hole 5 (and no use at hole 6) (Fig. 6). With water supplies reduced about $50 \%$ in late spring, hole 4 was also being actively used, and during the rest of the year hole 5 also actively supplied water. Hole 6 received some use during early and late summer, but at a significantly lower rate than holes 1 to 5 . This is indicated in Figure 6 by the rate of extraction at hole 6 being higher than the dead-tree rate but lower than the live-tree regression rate at the same starting volume percent available.

One additional facet of the extraction of soil water by velvet mesquite that is apparent in Figure 6 is the strong tendency for available moisture at the start of each constant-use period to be lowest for hole 1, next to the trunk, and to increase at successively farther holes. This probably is due in part to smaller recharge under the crowns 
because of interception losses, but mostly to the fact that, during the recharge periods prior to the start of the early spring and early summer periods of constant use, water use by the trees was heaviest under the crowns and decreased with distance beyond the crowns. The residual water contents at the start of the constant-use periods, therefore, were lowest under the crowns and increased with distance. Evapotranspiration was higher during the early summer recharge period than during the early spring recharge period, and more pronounced under the trees than in the openings. This led to greater differences in available water among holes at the start of the following constant-use period in early summer than in early spring (Fig. 6).

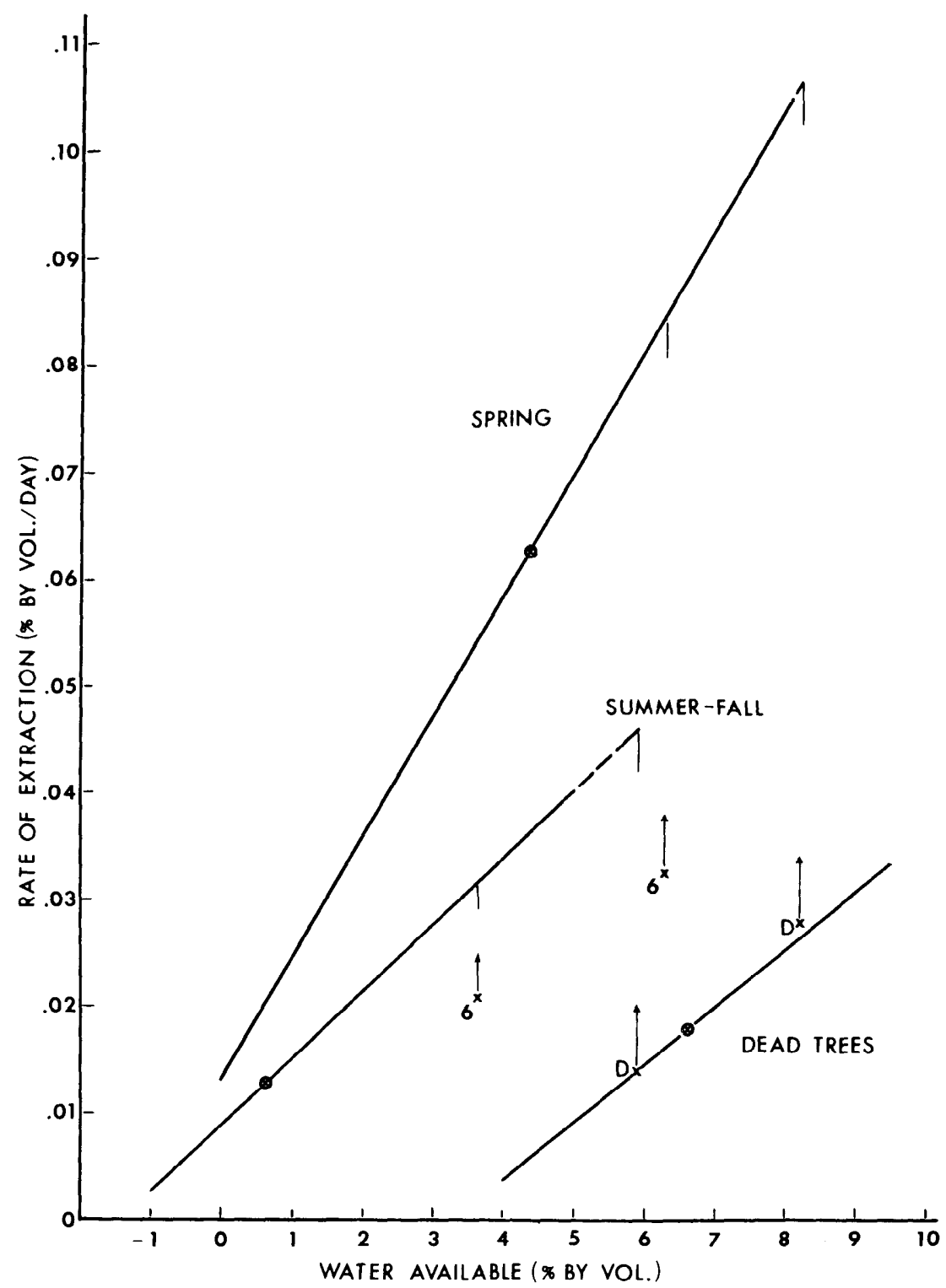

Fig. 7. Rates of extraction of soil water at deeper depths $(125-300 \mathrm{~cm}$ for spring, $75-300 \mathrm{~cm}$ for summer-fall) for holes $1-5$, in 1973, related to vol \% water available, compared with losses at dead trees (all seasons, $100-300 \mathrm{~cm}$ ). was:
In deeper soil layers. At soil depths below about $75 \mathrm{~cm}$, the relationship between amount of available water and rate of extraction is simpler, because evaporative influences are small or absent. Thus, a single equation describes the relationship during summer and fall for a relatively large part of the soil mass occupied by the mesquite roots -75 to $300 \mathrm{~cm}$ depths and holes 1 through 5-and for most of the crop year. During these periods available water did not exceed about $5 \%$ and rates of extraction were less than $0.05 \%$ by vol/day (Fig. 7). The relationship

Rate of extraction $=0.0090+0.0063$ (vol percent available at start of period).

Standard error of estimate is 0.0029 (Fig. 7). Differences in volume of water to the uniformity of response among depths during the drier summer and fall. Starting water contents at depths below $100 \mathrm{~cm}$ were relatively high, mostly between 3 and $9 \%$ at holes 1 to 5 , and rates of extraction were also relatively high (mostly 0.055 to $0.095 \%$ by vol/day). Here, again, differences in starting available water volumes accounted for about $88 \%$ of the differences in rates of extraction during the period for individual depths.

At depths of 50 to $100 \mathrm{~cm}$, available soil water and rates of extraction both varied within such narrow limits that regressions were not meaningful. Both averaged somewhat higher than for the 125- to $300-\mathrm{cm}$ data.

The portion of the water loss at the deeper depths that can be attributed to the mesquite trees can be approximated, as with the $25-\mathrm{cm}$ data, by comparing the regressions in Figure 7 for similar starting water contents. Thus, in the spring period the dead-tree extraction rate averaged about onefourth the live-tree rate, as shown by a vertical projection of the dead-tree available water content of $8.2 \%$ to the spring regression line in Figure 7 . Similarly, during the summer-fall period, the dead-tree rate of extraction was only $30 \%$ of the live-tree rate.

The greater dependence of the mesquite trees on hole 6 during summer and fall of 1973, is shown in Figure 8. Data for the $100-\mathrm{cm}$ depth illustrate that, when soil water was abundant (spring), the mesquite obtained essentially all of its water from the first 5 holes. As this moisture was depleted in early summer, the rate of extraction at hole 6 began to increase; hole 6 was then the 


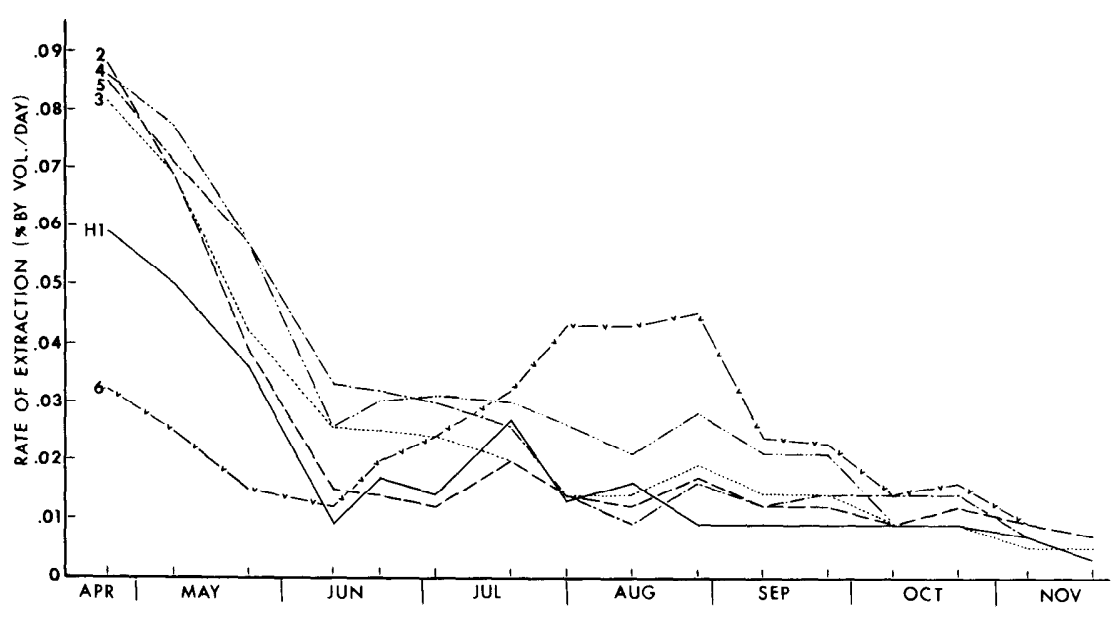

Fig. 8. Increasing dependence on hole 6 ( $15 \mathrm{~m}$ beyond edge of crown) for water as soil water closer to the trees is depleted (3-period moving average rate of extraction, $100-\mathrm{cm}$ depth. April to December, 1973).

major source of water during the dry summer and early fall. Data for other depths showed a similar pattern.

The data presented in Figures 7 and 8 , however, do not fully reflect the importance to mesquite of the water supplies present at the farther distances (holes 5 and 6). For example, at $20 \mathrm{~m}$ from the trunk of a tree, a $1-\mathrm{m}$ wide ring of soil around the tree contains twice the volume per unit of depth as a $1-\mathrm{m}$ wide ring of soil $10 \mathrm{~m}$ from the trunk. Thus, a given measured rate of extraction will result in the absorption of twice as much water $20 \mathrm{~m}$ from the tree as at $10 \mathrm{~m}$. The actual importance of water supplies at the farther distances is therefore greater than indicated by extraction rates alone.

\section{Summary and Conclusions}

Soil water contents ( $\%$ by vol) were measured by neutron probe at 13 depths from $25 \mathrm{~cm}$ to $6 \mathrm{~m}$ at six locations along one radius from each of four velvet mesquite trees (hole 1, next to the trunk; hole 6, $15 \mathrm{~m}$ beyond the edge of the crown, in an adjacent opening). Surrounding vegetation was killed so that the only live roots present were those of the study trees. Measurements were made under similar conditions near four similar trees that were killed, with no live roots of any kind near the access holes. Measurements were taken for $2 \frac{1}{2}$ years, 3 summers and 2 winters, at about 2 -week intervals.

Within this $2 \frac{1}{2}$-year study period, the soil water use regime for velvet mesquite is characterized by: (1) soil water recharge and depletion data for a summer of near-normal rainfall, and (2) depletion data during a very dry spring, summer, and fall following an unusually wet fall and winter recharge period.

Results are interpreted as follows:

1. Winter precipitation is much more effective in recharging the soil profile than is summer precipitation. Winter recharge reached a maximum depth of about $3 \mathrm{~m}$-highest at the 25-cm depth, decreasing with each successively greater depth. High evapotranspiration demands prevented percolation below about $1 \mathrm{~m}$ during the summer rainy period.

2. Essentially all available soil water from winter recharge is used before the end of the May-June drought, except in years when winter precipitation is appreciably higher than the longtime mean. In such years, carryover of soil water from spring to summer is higher in openings between trees (to 4 to $5 \%$ at hole 6 ) than under mesquite crowns ( 1 to $2 \%$ ).

3. Soil water is extracted most rapidly where and when available soil water is highest-usually at the $25-\mathrm{cm}$ depth immediately following precipitation periods. Varying amounts of available soil water accounted for 72 to $88 \%$ of the variation in extraction rates.

4. Stage of growth of the mesquite, during the leaf-bearing period, has little effect on rates of extraction of soil water.

5. Evaporation affects losses primarily at the $25-\mathrm{cm}$ depth, and to a much lesser extent at the $50-\mathrm{cm}$ depth.

6 . Roots of the mesquite trees extend out to at least $15 \mathrm{~m}$ beyond the edge of the crowns, but water is used at this distance primarily during drier periods when water supplies closer to the tree are depleted.

7. The trees consistently use water from next to the trunk out to $10 \mathrm{~m}$ beyond the edge of the crown. Rates of extraction are generally similar over this distance, for a given depth and similar amounts of available soil water.

8. When soil water levels are high, following recharge, extraction is initially highest at shallow depths, and successively greater depths are added to the active water supplying layer as the growing season advances. In contrast, when levels of available soil water are low, rates of extraction are also low and are similar throughout the profile.

9. The upper $37.5 \mathrm{~cm}$ of soil (as represented by the $25-\mathrm{cm}$ data) is an important source of soil water for velvet mesquite, and also is the major source of water for perennial grasses. Mesquite has the competitive advantage. This competitive effect extends into adjacent openings to at least $15 \mathrm{~m}$ beyond the edge of the crowns, but is most severe nearest to the crowns, gradually decreasing with increasing distance. The competitive effect in the openings is much more severe in dry years than in wet years.

\section{Literature Cited}

Cable, Dwight R., and S. Clark Martin. 1964. Forage production and stocking rates on southern Arizona ranges can be improved. U.S. Forest Serv. Res. Note RM-30, 11 p. Rocky Mountain Forest and Range Exp. Sta., Fort Collins, Colo.

Cable, Dwight R., and F. H. Tschirley. 1961. Responses of native and introduced grasses following aerial spraying of velvet mesquite in southern Arizona. J. Range Manage. 14: 155-159.

Cowan, I. R., and F. L. Milthorpe. 1968. Plant factors influencing the water status of plant tissues. p. 137-193. In: T. T. Kozlowski (Ed.) Water deficits and plant growth. Academic Press, New York. 390 p.

Gardner, W. R. 1968. A vailability and measurement of soil water. p. 107-135. In: T. T Kozlowski (Ed.) Water deficits and plant growth. Academic Press, New York. 390 p.

Kramer, Paul J. 1969. Plant and soil water relationships. McGraw-Hill Book Co., New York. 482 p.

Martin, S. Clark, and Dwight R. Cable. 1962. Grass production high 14 years after mesquite control. Arizona Cattlelog 18(12):58-61.

Martin, S. Clark, and Dwight R. Cable. 1974. Managing semidesert grass-shrub rangesvegetation responses to precipitation, grazing. soil texture, and mesquite control. U.S. Dep. Agr. Tech. Bull. $1480.45 \mathrm{p}$

Meyer, Bernard S., and Donald B. Anderson. 1952. Plant physiology. 2nd Ed. D. Van Nostrand Co., Princeton, N.J. 784 p.

Parker, Kenneth W., and S. Clark Martin. 1952. The mesquite problem on southern Arizona ranges. U.S. Dep. Agr. Circ. 908. $70 \mathrm{p}$.

Slatyer, R. C. 1967. Plant-water relationships. Academic Press, New York. 366 p. 